\title{
VALOR NUTRICIONAL DE PRODUTOS DE ERVILHA EM COMPARAÇÃO COM A ERVILHA FRESCA ${ }^{1}$
}

\author{
Solange Guidolin CANNIATTI-BRAZACA ${ }^{2, *}$
}

\section{RESUMO}

O trabalho teve por objetivos avaliar a composição centesimal e os teores de minerais, taninos e a disponibilidade de ferro e digestibilidade de proteínas em produtos de ervilha comercializados em Piracicaba/SP, em comparação com a ervilha fresca. Ocorreram alterações na composição centesimal, especialmente nas fibras, que se apresentaram em maiores quantidades na ervilha fresca. Os teores de taninos foram baixos. O teor de ferro foi maior na ervilha fresca $(27,16 \mathrm{mg} / \mathrm{Kg})$ como também sua disponibilidade (28,5\%), em conjunto com a sopa liofilizada (27,08\%). O menor valor foi apresentado pela ervilha enlatada $(14,04 \%)$, seguida pela sopa creme congelada (17,81\%). Para a digestibilidade, a variação foi de 64,59 a $79,33 \%$, sendo a proteína da sopa liofilizada a de menor digestibilidade. Foi concluído que o consumo de ervilha fresca seria o mais recomendado do ponto de vista nutricional, considerando os parâmetros analisados.

Palavras-chave: digestibilidade, proteínas, disponibilidade, ferro, antinutricionais, composição.

\section{SUMMARY}

NUTRITIONAL VALUE OF PEA PRODUCTS IN COMPARISON TO FRESH PEAS. The aim of this research was to evaluate the composition, amount of minerals and tannin, and iron availability in pea products sold in the city of Piracicaba, São Paulo state, and compare them with fresh peas. Alterations occurred in the components of compositions, especially in fibers which presented a high quantity of fresh peas. Tannin was very low and iron was the highest in fresh peas $(27.16 \mathrm{mg} / \mathrm{Kg})$ also the availability (28.5\%), such as freeze drying soup (27.08\%). The lowest value was for canned peas (14.04\%), in sequence freezing soup (17.81\%). The digestibility range from 64.59 to $79.33 \%$, freeze drying soup presented the lowest digestibility. It was concluded that the consumption of fresh peas was the most recommended from a nutritional point of view, when the analysed parameters were considered.

Keywords: digestibility, proteins, availability, iron, antinutritionals, composition.

\section{1 - INTRODUÇÃO}

A anemia ferropriva, é o maior problema nutricional de prevalência mundial. Segundo a Organização Mundial da Saúde (OMS), há no mundo aproximadamente de 1,5 a 2 bilhões de casos.

Para suprir a necessidade de ferro, deve ser levada em consideração sua absorção e utilização, ou seja, a sua biodisponibilidade, que é definida como a porção do nutriente na dieta ou no alimento que possa ser utilizado no organismo.

A diálise de ferro in vitro tem demonstrado bons resultados se comparada com a biodisponibilidade do ferro in vivo em seres humanos [18,32].

A biodisponibilidade do ferro pode ser influenciada por fatores como tratamento térmico e/ou processamento. Com relação aos fatores dietéticos, há aqueles que aumentam a absorção de ferro não heme e os que diminuem. Um dos fatores que diminui sua absorção são os inibidores de tripsina, lectina, ácido fítico e taninos.

\footnotetext{
${ }^{1}$ Recebido para publicação em 29/7/2005. Aceito para publicação em 20/10/2006 (001582)

${ }^{2}$ Departamento de Agroindústria, Alimentos e Nutrição,

Escola Superior de Agricultura "Luiz de Queiroz",

Universidade de São Paulo (USP), Av. Pádua Dias, 11, C. P. 9, CEP 13418-900, Piracicaba (SP), Brasil,

E-mail:sgcbraza@esalq.usp.br

* A quem a correspondência deve ser enviada
}

FERREIRA et al. [12] constataram que os taninos se alteram com diferentes condições de estocagem e com o amadurecimento de sementes de feijão guandu fresco. Dessa forma, tem-se maior ou menor influência deste componente no ferro não heme.

Os grãos de leguminosas são ricos em minerais, proteínas, carboidratos e vitaminas, especialmente do complexo B. Apresentam também componentes antinutricionais, como taninos e ácido fítico, os quais se ligam às proteínas e a alguns minerais como o ferro, inibindo sua biodisponibilidade [23].

Os teores de taninos das ervilhas estão relacionados à cor de suas flores, visto que as cultivares com flores coloridas apresentaram maior teor de taninos que as cultivares com cor branca. Os teores de taninos apresentaram influência no aproveitamento de nutrientes [28], assim como alta capacidade antioxidante, como constatado por AMAROWICZ et al. [4].

A princípio, a ervilha era cultivada tanto para forragem quanto como alimento. Na alimentação, era consumida na forma de grãos secos, moídos ou inteiros, ou na forma de grãos verdes. Com o desenvolvimento da indústria de alimentos, foram colocadas em prática formas alternativas de conservação da ervilha. Atualmente, é comercializada de várias formas, como: enlatada, congelada, na forma de farinhas, preparações ou frescas [8].

No mercado, encontramos muitos produtos de ervilha. O teor de ferro nesta leguminosa é de 1,54 mg/100 g para a 
ervilha fresca cozida; na enlatada, 0,95 mg/100 g; na congelada, 2,40 mg/100 g; e para produtos desidratados, como por exemplo sopa, 2,69 mg/100 g [11].

A forma de preparação dos alimentos de origem vegetal pode interferir na sua biodisponibilidade [26].

Pelo exposto acima, o objetivo deste estudo foi o de avaliar a composição centesimal e os teores de fibra solúvel e insolúvel, minerais, taninos, ácido fítico, digestibilidade da proteína e a disponibilidade de ferro em produtos de ervilha em comparação com a ervilha fresca.

\section{2 - MATERIAL E MÉTODOS}

\section{1 - Matéria-prima e preparo das amostras}

A matéria-prima utilizada para a realização das análises foi adquirida no comércio de Piracicaba/SP. Os produtos de ervilha utilizados foram os seguintes: Creme liofilizado (sopa liofilizada); enlatada (enlatada); Creme congelado (sopa congelada); seca (seca); e fresca (fresca).

As amostras foram preparadas com água deionizada, em panelas e utensílios em aço inox, na forma indicada para consumo, no caso das sopas, conforme indicação do preparo na embalagem. A ervilha fresca e a seca foram cozidas em água fervente até se tornarem tenras (5 e 10 min, respectivamente) e a água da cocção desprezada. Para a ervilha enlatada, não foi realizada nenhuma preparação, somente a água foi desprezada. Para as análises de digestibilidade da proteína e diálise de ferro, foi utilizada a amostra tal como para o consumo, sem a realização da secagem. Para as demais análises, as amostras foram secas e trituradas em moinhos de facas, peneiradas em malha de 30 "mesh", obtendo-se assim as farinhas a serem utilizadas para análises. O material foi armazenado em sacos de polietileno, fechados, à temperatura de $4{ }^{\circ} \mathrm{C}$.

Todas as análises foram realizadas em triplicata.

\section{2 - Composição centesimal}

As análises químicas de teor de matéria seca, proteína bruta, extrato etéreo e de cinzas foram realizadas de acordo com a metodologia indicada pela AOAC [7].

O teor de fibra dietética foi determinado de acordo com o proposto por ASP et al. [6], que utiliza enzimas e são obtidas as frações de fibra solúvel e insolúvel presentes nas amostras, sendo a soma o total.

\section{3 - Minerais}

Os minerais foram determinados pelo método descrito por SARRUGE \& HAAG [24], sendo utilizada a digestão com ácido nítrico perclórico a $50{ }^{\circ} \mathrm{C}$ por 10 a $15 \mathrm{~min}$, a $100{ }^{\circ} \mathrm{C}$ até digerir todo o material e atingir temperatura de $150{ }^{\circ} \mathrm{C}$. Após resfriamento e diluição do material com água deionizada, foi realizada a leitura em espectrofotômetro de absorção atômica, modelo PERKIM-ELMER 3.110, para cálcio, magnésio, cobre, manganês, zinco e ferro; espectrofotômetro colorimétrico para o fósforo e enxofre; e fotômetro de chama para sódio e potássio.

\section{4 - Digestibilidade de proteína in vitro}

A digestibilidade in vitro foi determinada segundo metodologia descrita por AKESON \& STAHMAN [1], a qual é baseada na hidrólise enzimática das proteínas com pepsina e pancreatina, seguida da determinação do nitrogênio não precipitável com ácido pícrico.

\section{5 - Disponibilidade de ferro in vitro}

A diálise foi realizada segundo método proposto por WHITTAKER, SPIVEY \& FORBES [32]. As amostras foram submetidas à digestão in vitro, com incubação a $37{ }^{\circ} \mathrm{C}$, o material obtido foi colocado em saco de diálise e medido o ferro dialisado.

\section{6 - Fatores antinutricionais}

\subsection{1 - Taninos}

Os taninos foram analisados segundo a metodologia descrita por PRICE, HAGERMAN \& BUTLER [21], por meio da extração com metanol e reação colorimétrica com solução de vanilina a $1 \%$ em metanol, deixados a $30{ }^{\circ} \mathrm{C}$ por $20 \mathrm{~min}$ e, posteriormente, a leitura em espectrofotômetro Beckman modelo DU 640 a $500 \mathrm{~nm}$. A concentração de taninos foi obtida a partir de uma curva padrão de catequina, sendo os resultados expressos em \% de taninos.

\subsection{2 - Ácido fítico}

O teor de ácido fítico foi determinado segundo o método de GRYNSPAN \& CHERYAN [13]. A amostra foi colocada em solução digestora e, posteriormente, centrifugada; o sobrenadante diluído em água destilada e eluído por resina e algodão, e depois $\mathrm{NaCl}$. Ao eluído foi adicionado o reativo de Wande, e a leitura foi realizada em espectrofotômetro a $500 \mathrm{~nm}$. O teor de ácido fítico foi obtido a partir da construção de curva padrão, sendo os resultados expressos em $\mathrm{mg} / \mathrm{g}$ de amostra.

\subsection{3 - Análise estatística}

O delineamento estatístico empregado foi o inteiramente ao acaso com comparação das médias obtidas nos diferentes tratamentos analisadas segundo Tukey em nível de 5\% [20], sendo utilizado o software SAS [25].

\section{3 - RESULTADOS E DISCUSSÃO}

Os resultados obtidos, em base fresca e seca, são apresentados nas tabelas de 1 a 8 .

O menor teor de umidade (Tabela 1) foi obtido para a ervilha seca, devido às alterações que ocorreram pelo 
processo de secagem dificultando sua reidratação. Outros produtos apresentaram valores superiores aos encontrados na fresca.

O teor de cinzas foi maior na enlatada devido à adição de sais que são utilizados em seu processamento. Os valores da sopa liofilizada e da ervilha enlatada estão acima do apresentado por HABIBA [14], porém os demais produtos estão com valores próximos ao apresentado nessa literatura.

A sopa liofilizada e a sopa congelada apresentaram teores mais elevados de extrato etéreo, pois apresentam em sua composição outros produtos além da ervilha.

O teor protéico se manteve maior para a fresca e o menor teor, para a sopa liofilizada; o mesmo ocorrendo para a fibra dietética. Segundo HABIBA [14], o teor de proteína na matéria seca foi de 25,6 a 27,2\%, estando dentro dos valores encontrados nessa pesquisa para os produtos de ervilha que foram de 12,53 a 28,72\% (Tabela 2), estando estes dados também de acordo com os apresentados por IGBASAN, GUENTER \& SLOMINSKI [17], que encontraram valores semelhantes para fibras e carboidratos. O menor teor de carboidratos foi encontrado para a sopa liofilizada e o maior, para a ervilha enlatada e para a seca.

Como pode ser verificado na Tabela 3, as fibras solúveis estão presentes na ervilha em maiores quantidades. A fibra insolúvel se encontra em maiores porcentagens na fresca e, em seguida, na sopa congelada. Os menores valores foram encontrados na enlatada para a fibra solúvel e para a sopa liofilizada na insolúvel. Existe maior quantidade de fibra insolúvel do que solúvel na ervilha. A fibra solúvel das leguminosas tem importante papel no controle de colesterol e na glicemia pós prandial [5, 9, 27].

Em base seca (Tabela 4 ) pôde ser verificado que a ervilha seca é a que tem maior quantidade de fibra solúvel e a menor quantidade de fibra insolúvel.

Nas Tabelas 5 e 6 , podem ser observadas as quantidades de minerais presentes nos produtos de ervilha e na ervilha fresca.

A quantidade de cálcio apresentou variação para as preparações sendo que a ervilha seca e a sopa liofilizada foram as que apresentaram os menores valores. O magnésio apresentou maiores níveis para a ervilha fresca e para a sopa congelada, enquanto que outros produtos apresentaram valores inferiores para este elemento.

A quantidade de zinco apresentada pela ervilha fresca foi maior que para outras amostras, assim como ocorreu para outros minerais, como o manganês, cobre e fósforo. Para estes elementos, a sopa liofilizada apresentou as menores

concentrações. A quantidade de ferro nas amostras está em acordo com os níveis apresentados pela USDA [11].

As preparações não apresentaram diferenças nas quantidades de ferro e enxofre. Já a quantidade de sódio na ervilha enlatada foi a mais elevada devido à utilização de aditivos em seu processamento.

As quantidades dos minerais analisados estão de acordo com o encontrado por ALONSO et al. [3].

TABELA 1 - Composição centesimal da ervilha fresca e seus produtos (base fresca).

\begin{tabular}{lllccrr}
\hline Amostras & Umidade (\%) & Cinza (\%) & Extrato Etéreo (\%) & Proteína (\%) & Fibra Dietética (\%) & Carb. por dif. (\%) \\
\hline Sopa L. & $92,31 \pm 0,0^{1 \mathrm{a} 2}$ & $0,97 \pm 0,0^{\mathrm{b}}$ & $1,11 \pm 0,0^{\mathrm{a}}$ & $0,96 \pm 0,0^{\mathrm{e}}$ & $1,18 \pm 0,0^{\mathrm{d}}$ & 3,42 \\
Enlatada & $77,50 \pm 0,0^{\mathrm{c}}$ & $1,23 \pm 0,0^{\mathrm{a}}$ & $0,37 \pm 0,0^{\mathrm{c}}$ & $3,99 \pm 0,2^{\mathrm{d}}$ & $3,76 \pm 0,1^{\mathrm{c}}$ & 11,97 \\
Sopa C. & $79,37 \pm 0,0^{\mathrm{b}}$ & $0,63 \pm 0,0^{\mathrm{d}}$ & $1,20 \pm 0,1^{\mathrm{a}}$ & $5,55 \pm 0,4^{\mathrm{c}}$ & $6,85 \pm 0,0^{\mathrm{b}}$ & 7,84 \\
Seca & $74,85 \pm 0,0^{\mathrm{e}}$ & $0,62 \pm 0,0^{\mathrm{d}}$ & $0,40 \pm 0,0^{\mathrm{c}}$ & $6,12 \pm 0,1^{\mathrm{b}}$ & $3,46 \pm 0,0^{\mathrm{c}}$ & 12,79 \\
Fresca & $76,43 \pm 0,0^{\mathrm{d}}$ & $0,93 \pm 0,0^{\mathrm{c}}$ & $0,90 \pm 0,1^{\mathrm{b}}$ & $6,77 \pm 0,1^{\mathrm{a}}$ & $8,07 \pm 4,4^{\mathrm{a}}$ & 9,47 \\
\hline
\end{tabular}

${ }^{1}$ Média \pm Desvio padrão; ${ }^{2}$ Letras diferentes na vertical indicam diferença estatística entre as médias $(\mathrm{p} \leq 0,05)$.

TABELA 2 - Composição centesimal da ervilha fresca e seus produtos (base seca).

\begin{tabular}{|c|c|c|c|c|c|}
\hline Amostras & Cinza (\%) & Extrato Etéreo (\%) & Proteína (\%) & Fibra Dietética (\%) & Carb. por dif. (\%) \\
\hline Sopa L. & $12,67 \pm 0,0^{1 \mathrm{a} 2}$ & $14,38 \pm 0,1^{a}$ & $12,53 \pm 0,1^{d}$ & $15,36 \pm 0,0^{d}$ & 45,06 \\
\hline Enlatada & $5,44 \pm 0,1^{b}$ & $1,64 \pm 0,1^{d}$ & $17,72 \pm 0,7^{c}$ & $16,72 \pm 0,3^{c}$ & 58,48 \\
\hline Sopa C. & $3,05 \pm 0,0^{d}$ & $5,80 \pm 0,5^{b}$ & $26,92 \pm 1,7^{\mathrm{a}}$ & $33,19 \pm 0,2^{b}$ & 31,03 \\
\hline Seca & $2,47 \pm 0,0^{e}$ & $1,59 \pm 0,0^{d}$ & $24,32 \pm 0,4^{b}$ & $13,74 \pm 0,1^{\mathrm{e}}$ & 57,88 \\
\hline Fresca & $3,94 \pm 0,0^{c}$ & $3,83 \pm 0,4^{c}$ & $28,72 \pm 0,3^{a}$ & $34,22 \pm 0,0^{a}$ & 29,29 \\
\hline
\end{tabular}

${ }^{1}$ Média \pm Desvio padrão; ${ }^{2}$ Letras diferentes na vertical indicam diferença estatística entre as médias $(\mathrm{p} \leq 0,05)$.

TABELA 3 - Quantidade de fibras solúveis e insolúveis em ervilha fresca e seus produtos (base fresca).

\begin{tabular}{lcc}
\hline \multicolumn{1}{c}{ Amostras } & Fibra solúvel (\%) & Fibra insolúvel (\%) \\
\hline Sopa liofilizada & $0,08 \pm 0,0^{1 \mathrm{~d} 2}$ & $1,10 \pm 0,0^{\mathrm{e}}$ \\
Enlatada & $0,01 \pm 0,0^{\mathrm{e}}$ & $3,75 \pm 0,1^{\mathrm{c}}$ \\
Sopa congelada & $0,10 \pm 0,0^{\mathrm{c}}$ & $6,74 \pm 0,0^{\mathrm{b}}$ \\
Seca & $0,50 \pm 0,0^{\mathrm{a}}$ & $2,95 \pm 0,0^{\mathrm{d}}$ \\
Fresca & $0,37 \pm 0,0^{\mathrm{b}}$ & $7,70 \pm 0,0^{\mathrm{a}}$ \\
\hline
\end{tabular}

${ }^{1}$ Média \pm Desvio padrão; ${ }^{2}$ Letras diferentes na vertical indicam diferença estatística entre as médias ( $\mathrm{p} \leq 0,05)$
TABELA 4 - Guantidade de fibras solúveis e insolúveis em ervilha fresca e seus produtos (base seca).

\begin{tabular}{lcc}
\hline Amostras & Fibra solúvel (\%) & Fibra insolúvel (\%) \\
\hline Sopa liofilizada & $1,02 \pm 0,1^{1 \mathrm{c} 2}$ & $14,34 \pm 0,1^{\mathrm{c}}$ \\
Enlatada & $0,06 \pm 0,0^{\mathrm{e}}$ & $16,67 \pm 0,3^{\mathrm{b}}$ \\
Sopa congelada & $0,50 \pm 0,0^{\mathrm{d}}$ & $32,69 \pm 0,3^{\mathrm{a}}$ \\
Seca & $2,00 \pm 0,0^{\mathrm{a}}$ & $11,74 \pm 0,1^{\mathrm{d}}$ \\
Fresca & $1,55 \pm 0,0^{\mathrm{b}}$ & $32,68 \pm 0,0^{\mathrm{a}}$ \\
\hline
\end{tabular}

${ }^{1}$ Média \pm Desvio padrão; ${ }^{2}$ Letras diferentes na vertical indicam diferença estatística entre as médias $(\mathrm{p} \leq 0,05)$. 
TABELA 5 - Quantidade dos minerais, fósforo, potássio, cálcio, magnésio, enxofre, sódio, cobre, ferro, manganês e zinco, em ervilha fresca e seus produtos (base fresca).

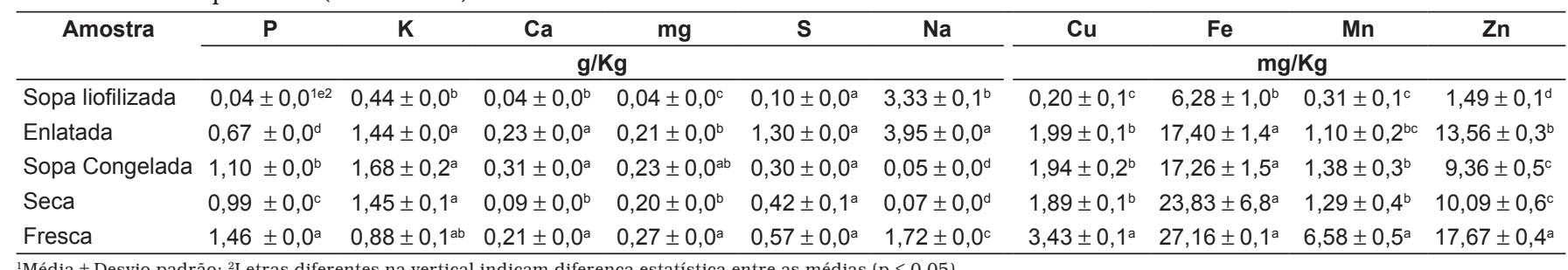

${ }^{1}$ Média \pm Desvio padrão; ${ }^{2}$ Letras diferentes na vertical indicam diferença estatística entre as médias $(\mathrm{p} \leq 0,05)$.

TABELA 6 - Quantidade dos minerais, fósforo, potássio, cálcio, magnésio, enxofre, sódio, cobre, ferro, manganês e zinco, em ervilha fresca e seus produtos (base seca).

\begin{tabular}{|c|c|c|c|c|c|c|c|c|c|c|}
\hline \multirow[t]{2}{*}{ Amostra } & $\mathbf{P}$ & $\mathbf{K}$ & $\mathrm{Ca}$ & $\mathrm{mg}$ & $\mathbf{S}$ & $\mathrm{Na}$ & $\mathrm{Cu}$ & $\mathrm{Fe}$ & Mn & $\mathrm{Zn}$ \\
\hline & \multicolumn{6}{|c|}{$\mathrm{g} / \mathrm{Kg}$} & \multicolumn{4}{|c|}{$\mathrm{mg} / \mathrm{Kg}$} \\
\hline Sopa liofilizada & $0,47 \pm 0,0^{12 e}$ & $5,78 \pm 0,5^{b}$ & $0,57 \pm 0,0^{c}$ & $0,51 \pm 0,0^{c}$ & $1,18 \pm 0,3^{b}$ & $43,32 \pm 1,4^{a}$ & $2,64 \pm 0,9^{c}$ & $81,64 \pm 12,9^{a b}$ & $4,08 \pm 1,0^{b}$ & $19,36 \pm 0,8^{e}$ \\
\hline Enlatada & $2,96 \pm 0,0^{d}$ & $6,38 \pm 0,0^{b}$ & $1,01 \pm 0,0^{b}$ & $0,94 \pm 0,0^{\mathrm{ab}}$ & $1,26 \pm 0,0^{b}$ & $17,54 \pm 0,0^{b}$ & $8,82 \pm 0,5^{b}$ & $77,34 \pm 6,0^{\mathrm{b}}$ & $4,90 \pm 1,1^{b}$ & $60,28 \pm 1,5^{b}$ \\
\hline Sopa Congelada & $5,31 \pm 0,2^{b}$ & $8,15 \pm 0,8^{a}$ & $1,49 \pm 0,1^{a}$ & $1,10 \pm 0,2^{a}$ & $1,47 \pm 0,0^{b}$ & $0,37 \pm 0,0^{d}$ & $9,41 \pm 1,1^{b}$ & $83,65 \pm 7,1^{a b}$ & $6,67 \pm 1,3^{b}$ & $45,39 \pm 2,5^{c}$ \\
\hline Seca & $3,93 \pm 0,1^{c}$ & $5,78 \pm 0,5^{b}$ & $0,38 \pm 0,0^{d}$ & $0,79 \pm 0,1^{b}$ & $1,65 \pm 0,1^{b}$ & $0,27 \pm 0,0^{d}$ & $7,52 \pm 0,3^{b}$ & $94,75 \pm 27,2^{\mathrm{ab}}$ & $5,11 \pm 1,6^{b}$ & $40,12 \pm 2,6^{d}$ \\
\hline Fresca & $6,17 \pm 0,1^{a}$ & $3,73 \pm 0,3^{c}$ & $0,90 \pm 0,1^{b}$ & $1,14 \pm 0,1^{a}$ & $2,40 \pm 0,1^{a}$ & $7,30 \pm 0,0^{c}$ & $14,57 \pm 0,2^{a}$ & $115,23 \pm 0,2^{a}$ & $27,92 \pm 2,2^{a}$ & $74,95 \pm 1,7^{a}$ \\
\hline
\end{tabular}

${ }^{1}$ Média \pm Desvio padrão; ${ }^{2}$ Letras diferentes na vertical indicam diferença estatística entre as médias $(\mathrm{p} \leq 0,05)$.

Para os minerais, pode ser observado que a ervilha fresca apresenta maiores concentrações de minerais, sendo nutricionalmente importante o seu consumo quando se considera o teor total. Já o consumo de sopa liofilizada contém as menores quantidades de minerais, mesmo se forem considerados os teores de minerais na matéria seca. A disponibilidade do ferro para a fresca e a sopa liofilizada foi igual (Tabela 9), porém se for calculada a quantidade de ferro disponível para absorção para a fresca tem-se 0,774 mg e para a sopa liofilizada, 0,170 mg, considerando-se o consumo de $100 \mathrm{~g}$ dos produtos.

As amostras de ervilha não apresentaram quantidades elevadas de taninos (Tabelas 7 e 8), como também constatado por ALONSO et al. [3], não sendo um fator que irá influenciar na diálise do ferro e no aproveitamento das proteínas,

TABELA 7 - Teores de taninos (mg/g) e ácido fítico (mg/g) em ervilha fresca e seus produtos (base fresca).

\begin{tabular}{lcc}
\hline \multicolumn{1}{c}{ Amostras } & Taninos $(\mathbf{~ m g} / \mathbf{g})$ & Ácido fítico $(\mathbf{~ m g} / \mathbf{g})$ \\
\hline Sopa liofilizada & 0 & $0,10 \pm 0,0^{\mathrm{c}}$ \\
Enlatada & 0 & $0,57 \pm 0,0^{\mathrm{b}}$ \\
Sopa Congelada & $0,19 \pm 0,0^{1 \mathrm{a} 2}$ & $0,55 \pm 0,0^{\mathrm{b}}$ \\
Seca & $0,12 \pm 0,0^{\mathrm{b}}$ & $0,67 \pm 0,0^{\mathrm{ab}}$ \\
Fresca & 0 & $0,70 \pm 0,0^{\mathrm{a}}$ \\
\hline
\end{tabular}

${ }^{1}$ Média \pm Desvio padrão; ${ }^{2}$ Letras diferentes na vertical indicam diferença estatística entre as médias $(\mathrm{p} \leq 0,05)$.

TABELA 8 - Teores de taninos (mg/g) e ácido fítico (mg/g) em ervilha fresca e seus produtos (base seca).

\begin{tabular}{lcc}
\hline \multicolumn{1}{c}{ Amostras } & Taninos $(\mathbf{m g} / \mathbf{g})$ & Ácido fítico $(\mathbf{m g} / \mathbf{g})$ \\
\hline Sopa liofilizada & 0 & $1,26 \pm 0,2^{\mathrm{c}}$ \\
Enlatada & 0 & $2,53 \pm 0,0^{\mathrm{b}}$ \\
Sopa Congelada & $0,93 \pm 0,0^{1 \mathrm{a} 2}$ & $2,64 \pm 0,0^{\mathrm{b}}$ \\
Seca & $0,50 \pm 0,0^{\mathrm{b}}$ & $2,68 \pm 0,1^{\mathrm{b}}$ \\
Fresca & 0 & $2,97 \pm 0,1^{\mathrm{a}}$ \\
\hline
\end{tabular}

$\overline{{ }^{1} \text { Média } \pm \text { Desvio padrão; }{ }^{2} \text { Letras diferentes na vertical indicam diferença estatística entre }}$ as médias $(\mathrm{p} \leq 0,05)$. quando a ervilha estiver nesta forma de consumo, pois as quantidades de taninos e ácido fítico são muito baixas e não afetarão o aproveitamento do ferro e da proteína. Esta pequena quantidade se deve ao processamento sofrido pelas amostras [14]. WANG et al. [31] também não detectaram taninos em várias cultivares analisadas e, nas demais, os teores apresentados foram muito baixos.

Segundo MARTINEZ \& MOYANO [19], os teores de taninos necessários para afetar a hidrólise das proteínas são maiores do que os encontrados nas amostras.

Segundo HURRELL [16], pequenas quantidades do ácido fítico ( $100 \mathrm{mg} / 100 \mathrm{~g}$ ) podem duplicar e, em taxas menores, até quintuplicar a disponibilidade do ferro. Devido à baixa quantidade de ácido fítico encontrada nos produtos analisados, não foi observado este efeito.

Alguns fatores que influenciam na quantidade de taninos são: estocagem, grau de amadurecimento, cor das flores das diferentes variedades [12, 28].

Os valores de taninos encontrados para outras leguminosas são maiores do que os da ervilha, como constatado por ALONSO et al. [2], que encontraram para Vicia fava teores de taninos condensados variando de 0,15 a $1,95 \mathrm{~g} / \mathrm{Kg}$; e para Phaseolus vulgaris, valores de 0,25 a $3,59 \mathrm{~g} / \mathrm{Kg}$. Para a ervilha crua, o valor de taninos foi de $0,24 \mathrm{~g} / \mathrm{Kg}$ e de $0,02 \mathrm{~g} / \mathrm{Kg}$ para a extrusada [3].

A disponibilidade de ferro é influenciada por vários fatores que, quando levados em consideração em conjunto, podem dar uma idéia de quanto será absorvido em uma refeição, como a equação proposta por HALLBERG \& HULTHEN [15]. Os fatores presentes nas refeições que são levados em consideração são as quantidades de fitato, polifenóis, ácido ascórbico, carne, peixe e produtos marinhos, cálcio, ovo, proteína de soja e álcool. Nessa equação proposta, é levado em consideração a relação de dose efeito. Segundo THOMPSON [29] e REDDY \& PIERSON [22], os compostos 
TABELA 9 - Diálise de ferro e digestibilidade da proteína da ervilha fresca e seus produtos.

\begin{tabular}{lcc}
\hline \multicolumn{1}{c}{ Amostra } & Diálise de ferro (\%) & $\begin{array}{c}\text { Digestibilidade de } \\
\text { proteína (\%) }\end{array}$ \\
\hline Sopa liofilizada & $27,08 \pm 0,9^{1 \mathrm{a} 2}$ & $64,59 \pm 0,8^{\mathrm{b}}$ \\
Enlatada & $14,04 \pm 0,5^{\mathrm{d}}$ & $72,34 \pm 1,2^{\mathrm{a}}$ \\
Sopa congelada & $17,81 \pm 0,6^{\mathrm{c}}$ & $79,33 \pm 1,7^{\mathrm{a}}$ \\
Seca & $22,83 \pm 0,2^{\mathrm{b}}$ & $77,13 \pm 0,9^{\mathrm{a}}$ \\
Fresca & $28,50 \pm 1,0^{\mathrm{a}}$ & $79,19 \pm 0,4^{\mathrm{a}}$ \\
\hline
\end{tabular}

${ }^{1}$ Média \pm Desvio padrão; ${ }^{2}$ Letras diferentes na vertical indicam diferença estatística entre as médias $(\mathrm{p} \leq 0,05)$

fosforilados, como os inositol fosfatos, fibras e taninos, são os principais componentes alimentares que diminuem o aproveitamento dos minerais.

A disponibilidade do ferro em produto infantil de ervilha aumentou de $20,7 \%$ para $33,1 \%$ quando o ácido fítico foi degradado, indicando que a diminuição do seu teor é importante para a melhora do aproveitamento do ferro. No mesmo produto, quando foi aumentada a taxa de ácido ascórbico (de $14,8 \%$ para $22,1 \%$ ), ocorreu aumento do ferro disponível para absorção [9].

Os métodos de processamento modificam a composição e a disponibilidade de nutrientes em relação ao material cru [10, 30]. Porém, alterações químicas produzidas pelo processo de aquecimento podem também diminuir a assimilação de nutrientes, incluindo a absorção de certos nutrientes [2]. O processo de liofilização da sopa não afetou a disponibilidade do ferro, não diferindo da ervilha fresca, já os demais processos afetaram, sendo que a amostra que apresentou a menor disponibilidade foi a enlatada, seguida pela sopa congelada e a ervilha seca. A presença de polifenóis naturais pode ser inibitório na absorção de minerais, porém o conteúdo de taninos não foi substancial, para promover esta alteração, como constatado por ALONSO et al. [3]. O teor de fibra presente não influenciou na disponibilidade do ferro, já que a ervilha fresca apresentou as maiores quantidades e a melhor disponibilidade.

A disponibilidade de ferro in vivo para a ervilha crua foi de 0,135 e para a extrusada foi de 0,21, com a suplementação a disponibilidade do ferro foi menor [3].

A digestibilidade da proteína variou de $73,5 \%$ (ervilha crua) a $78,3 \%$ para cocção em autoclave por 15 min ou cocção em panela aberta por 40 min [14]. Alguns produtos analisados apresentaram digestibilidade da proteína maior, como a ervilha fresca, sendo que a menor digestibilidade foi apresentada pela sopa liofilizada, provavelmente devido ao processo de liofilização do produto.

\section{4 - CONCLUSÓES}

- O consumo de ervilha fresca em relação a seus produtos encontrados no mercado tem grande variação na composição centesimal;

- O teor de fibras solúveis e insolúveis é maior na ervilha fresca, indicando que os processamentos empregados para a obtenção dos produtos diminuem estes elementos de suma importância para a saúde;

- Para a maior parte dos minerais analisados a ervilha fresca apresentou os maiores teores;

- Os antinutricionais analisados apresentaram quantidades baixas em todas as amostras analisadas, indicando que não há preocupação quanto às interações com nutrientes; e

- A disponibilidade do ferro encontrada para a ervilha e seus produtos é muito boa; mesmo se for considerada a ervilha enlatada, a digestibilidade da proteína é razoável.

Portanto, o consumo de ervilha fresca seria o mais recomendado do ponto-de-vista nutricional, considerando os parâmetros analisados.

\section{5 - REFERÊNCIAS BIBLIOGRÁFICAS}

[1] AKESON, W. R.; STAHMANN, M. A. A pepsin pancreatin digest index of protein quality evaluation. The Journal of Nutrition, Bethesda, v. 83, n. 3, p. 257 - 261, jul. 1964.

[2] ALONSO, R.; AGUIRRE, A.; MARZO, F. Effects of extrusion and traditional processing methods on antinutrients and in vitro digestibility of protein and starch in fava and kidney beans. Food Chemistry, Oxford, v. 68, n. 2, p. 159-165, feb. 2000.

[3] ALONSO, R. et al. Effects of extrusion cooking on mineral bioavailability in pea and kidney bean seed meals. Animal Feed Science and Technology, Amsterdam, v. 94 , n. 1-2, p. 1-13, nov. 2001.

[4] AMAROWICZ, R. et al. Antioxidant activity of condensed tannins of beach pea, canola hulls, evening primrose, and faba bean. Journal of Food Lipids, Trumbull, v. 7, n. 3, p. 195-205, sep. 2000.

[5] ARAYA, H., et al. Digestion rate of legume carbohydrates and glycemic index of legume-based meals. International Journal of Food Sciences and Nutrition, Hants, v. 54, n. 2, p. 119-126, mar. 2003.

[6] ASP, N. G., et al. Rapid enzymatic assay of insoluble and soluble dietary fiber. Journal of Agricultural and Food Chemistry, Washington, v. 31, n. 3, p. 476-482, may 1983.

[7] ASSOCIATION OF OFFICIAL ANALYTICAL CHEMISTS AOAC Official Methods of Analysis of Association of official Analytical Chemists, 16.ed. Washington: AOAC. 1995. v. 2.

[8] COUTO, F. A. A. Aspectos históricos e econômicos da cultura da ervilha. Informe Agropecuário, Belo Horizonte, v. 158, p. 5-7, n. 158, 1989.

[9] DAVIDSSON, L. et al. Iron absorption from experimental infant formulas based on pea (Pisum sativum)-protein isolate: the effect of phytic acid and ascorbic acid. British Journal of Nutrition, Oxon, v. 85, n. 1, p. 59-63, jan. 2001.

[10] DELlaVAlle, G.; QUILliEN, L.; GUEGUEN, J. Relationships between processing conditions and starch and protein modifications during extrusion-cooking of pea 
flour. Journal of the Science of Food and Agriculture, Sussex, v. 46, n. 4, p. 509-517, apr. 1994.

[11] ESTADOS UNIDOS. Food and Nutrition Information Center. Nutrient database for standard reference Release 14. Disponível em : <http://www.nal.usda.gov/fnic> acesso em: 13 maio 2004.

[12] FERREIRA, E. C., et al. Effect of drying method and length of storage on tannin and total phenol concentrations in Pigeon pea seeds. Food Chemistry, Oxford, v. 86 , n. 1, p. 17-23, jun. 2004.

[13] GRYNSPAN, F.; CHERYAN, M. Phytate-calcium interaction with soy protein. Journal of the American Oil Chemists Society, Champaign, v. 66, n. 1, p. 93-97, jan. 1989.

[14] HABIBA, R. A. Changes in anti-nutrients, protein solubility, digestibility and $\mathrm{HCl}$-extractability of ash and phosphorus in vegetable peas as affected by cooking methods. Food Chemistry, Oxford, v. 77, n. 2, p. 187-192, may 2002.

[15] HALLBERG, L.; HULTHEN, L. Prediction of dietary iron absorption: an algorithm for calculating absorption and bioavailability of dietary iron American Journal of Clinical Nutrition, Bethesda, v. 71, n. 5, p. 1147-1160, may 2000.

[16] HURRELL, R. F. Influence of vegetable protein sources on trace element and mineral bioavailability. The Journal of Nutrition, Bethesda, v. 133, n. 9, p. 2973S-2.977S, sep. 2003

[17] IGBASAN, F. A.; GUENTER, W.; SLOMINSKI, B. A. Field peas: chemical composition and energy and amino acid availabilities for poultry. Canadian Journal of Animal Science, Ottawa, v. 77, n. 2, p. 293-300, jun. 1997.

[18] LUTEN, J. et al. Interlaboratory trial on the determination of the In vitro iron dialysability from food. Journal of the Science of Food and Agriculture, Sussex, v. 72, n. 4, p. 415-424, dec. 1996.

[19] MARTINEZ, T. F.; MOYANO, F. J. Effect of tannic acid on in vitro enzymatic hydrolysis of some protein sources. Journal of the Science of Food and Agriculture, Sussex, v. 83, n. 5, p. 456-464, apr. 2003.

[20] PIMENTEL - GOMES, F. Curso de estatística experimental. 10 ed. São Paulo: Nobel, 1982, 468 p.

[21] PRICE, M. L.; HAGERMAN, A. E.; BUTLER, L. G. Tannin content of cowpeas, chickpeas, pigeon peas, and human mung beans. Journal of Agricultural and Food Chemistry, Washington, v. 28, n. 2, p. 459-461, mar. 1980.

[22] REDDY, N. R.; PIERSON, M. D. Reduction in antinutritional and toxic components in plant foods by fer- mentation. Food Research International, Amsterdam, v. 27, n. 3, p. 281-290, 1994.

[23] REYES-MORENO, C.; PAREDES-LOPEZ, O. Hard-tocook phenomenon in commom beans: a review. Critical Reviews in Food Science and Nutrition, Boca Raton, v. 33, n. 3, p. 227-286, 1993.

[24] SARRUGE, J. R.; HAAG, H. P. Análises químicas em plantas, Piracicaba: ESALQ-USP, 1974. p. 56.

[25] SAS STATISTICAL ANALYSIS SYSTEM INSTITUTE. Sas/Qc software: usage and reference. 2. ed. NC: Cary, 1996. v. 2 (version 6).

[26] SAUNDERS C. et al. Utilização de tabelas de composição de alimentos na avaliação do risco de hipovitaminose A. Archivos Latinoamericanos de Nutricion, Caracas, v. 50, n. 3, p. 237-242, sep. 2000.

[27] SCHAFER, G., et al. Comparison of the effects of dried peas with those of potatoes in mixed meals on postprandial glicose and insulin concentrations in patients with type 2 diabetes. American Journal of Clinical Nutrition, Bethesda, v. 78, n. 1, p. 99-103, jul. 2003.

[28] SMULIKOWSKA, S. et al. Tannin content affects negatively nutritive value of pea for monogastrics. Journal of Animal and Feed Sciences, Jablonna, v. 10, n. 3, p. 511-523, 2001.

[29] THOMPSON, L. U. Potential health benefices and problems associated with antinutrients in food. Food Research International, Ontario, v. 26, n. 2, p. 131-149, 1993.

[30] VAN DER POEL, A. F. B. ZUILICHEM, D. J., VAN OORT, M. G. Thermal inativation of lectins and trypsin inhibitor activity during steam processing of dry beans (Phaseolus vulgaris L.) and effects on protein quality. Journal of the Science of Food and Agriculture, Sussex, v. 53, n. 2, p. 215-228, 1990 .

[31] WANG, X. F., et al. Total phenolics and condensed tannins in field pea (Pisum sativum L.) and grass pea (Lathyrus sativus L.). Euphytica, Dordrecht, v. 101, n. 1, p. 97-102, may 1998.

[32] WHITTAKER, P.; FOX, M. R. S.; FORBES, A. L. In vitro prediction of iron bioavailability for food fortification. Nutrition Reports International, Woburn, v. 39, n. 6, p. 1205-1215, jun. 1989.

\section{6 - AGRADECIMENTOS}

A autora agradece à FAPESP, pelo auxílio financeiro para a realização do projeto, e às alunas de iniciação científica Elen Caroline Sano Zoriki, pelas análises químicas, e Taís Carolina Franqueira de Toledo, pelas análises estatísticas iniciais. 